\title{
Empirical Research on Relationship of Caddies' Reward Satisfaction, Organizational Commitment and Turnover Intention
}

\author{
Xu Yongmei' ${ }^{1}$ Jiang Jiankai² \\ ${ }^{1}$ Department of Business Administration, Management School, Jinan University, Guangzhou, China \\ ${ }^{2}$ Enterprise Management, Management School, Jinan University, Guangzhou, China \\ Email: txuym@jnu.edu.cn
}

Received 19 March 2015; accepted 22 April 2015; published 4 May 2015

Copyright @ 2015 by authors and Scientific Research Publishing Inc.

This work is licensed under the Creative Commons Attribution International License (CC BY). http://creativecommons.org/licenses/by/4.0/

(c) (i) Open Access

\begin{abstract}
Based on the situation of turnover of golf caddies, we study the relationship of caddies' reward satisfaction, organizational commitment, and turnover intention in Shenzhen, China. The research shows that 1) caddies' gender, education, grade, and years of working make a significant difference in turnover intention; 2) caddies' reward satisfaction has a significant positive impact on organizational commitment, caddies' reward satisfaction, organizational commitment has a significant negative impact on turnover intention, and affective commitment and continuance commitment have a significant negative impact on turnover intention; 3) caddies' organizational commitment tends to mediate between the relationship of reward satisfaction and turnover intention. This paper also proposes some recommendations to improve caddies' reward satisfaction, organizational commitment, and reduce the turnover intention for golf club managers.
\end{abstract}

\section{Keywords}

Golf Caddie, Reward Satisfaction, Organizational Commitment, Turnover Intention

\section{Introduction}

The first golf club was opened in Zhongshan, Guangdong, China in 1984, and after that, golf in China is developing rapidly. Serving customer to play golf is the basic business in a club. There are 100 to 150 caddies in a media golf club, nearly $60 \%$ of all staff. As core staff of a club, previous research showed that caddis demission was very high. Turnover behavior generally comes from the external pulling force and pushing force inside the organization; pushing force mainly includes the perception and attitude of the workers. Sager suggests that the 
optimal estimation of departure behavior is turnover intention. Arnold and Feldman also suggest that work attitude (such as job satisfaction, organizational commitment) and demographic variables (e.g., age, seniority) are the important predictive value of employee turnover intention (Zhong Jianwei, 2008).

Reward of Chinese golf caddies consists of basic pay and piecework performance. It's so unstable that institution about reward has a great impact for the caddies. Dissatisfactory about reward is probably the main reason of leave act. Organizational commitment is staff's identity and investment for their organization and thus derives a kind of attitude and behavior. Previous empirical research also proves that the organizational commitment and turnover intention have a negative correlation. Therefore, we study the relationship of caddies' reward satisfaction, organizational commitment and turnover intention, considering the influence of demographic variables, and find out whether organizational commitment plays a role of mediating effect between reward satisfaction and turnover intention and to clarify whether golf caddie reward satisfaction and organizational commitment can be used to predict turnover intention.

\section{Literature Review}

\subsection{Literature Review of Reward Satisfaction, Organizational Commitment and Turnover Intention}

Generalized reward include direct reward (including basic salary, bonuses, incentive pay and other direct economic compensation), the indirect reward (including welfare and related services and other indirect economic rewards), the non-economic reward (including working environment, psychological income, etc.) (Zeng Xiangquan, 2003; Byars, L. L., \& Rue, L. W., 2005; Liu Xin, 2002). As an important measure of job satisfaction, reward satisfaction research began in the United States scholars Adams, he pointed out that reward satisfaction is due to the cause of the individual to pay fair feeling, this feeling comes from a complex process of perception and comparison. Ran B. suggests that reward satisfaction is a state of satisfaction after comparing the economic and non-economic reward obtained from the enterprise with expectations in their minds (Ran Bin, 2002). This paper argues that reward satisfaction include direct reward, an indirect reward and non-economic reward. The direct reward include basic wages, bonuses and incentive pay and other direct economic compensation, an indirect reward include welfare and related services, etc; non-economic reward including working environment and psychological income, etc.

Organizational commitment refers to the employee's commitment to the organization. It's put forward by the American sociologist Becker (Becker, H. S., 1960). In 1990, Allen and Meyer proposed organizational commitment theory of three factors model (Meyer, J. P. \& Allen, N. J., 1997) on the basis of research of Becker, Buchanan, Porter, Wiener (Robinson, S. L. \& Morrison, E. W., 1995; Robinson, S. L. \& Russeau, D. M., 1994; Wiener, Y., 1982). Organizational commitment has at least the following three dimensions: affective commitment, continuance commitment, normative commitment. AC (affective commitment, AC), mainly refers to the employees' emotional dependence, identity and input to the organization and the strength of personal identity to participate in the organization. CC (continuance commitment, CC), mainly reflect the loss cognition brought from employees leaving the organization, and thus have to continue in the organization. NC, normative commitment, NC), mainly reflects the sense of obligation and responsibility remain staying in the organization. It is primarily an individual in the social process of inner have a tendency to comply with specification.

Turnover intention is a psychological tendency that individuals want to leave current job and looking for new jobs (Yang Qingtao, 2010). Turnover intention is a withdrawal behavior when employees had not satisfied. When employees had not satisfied, the next process is turnover notion, and after several other steps (departure thought, looking for jobs, the comparative evaluation other jobs), turnover intention is the last step before actual turnover behavior (Adier, S. \& Skov, R., 1985).

Previous researches have study the relationship of reward satisfaction and organizational commitment taking knowledge staff, design staff, high school teachers as research object (Xin Xun, 2006; Huang Rui, 2011; Lai Xiaoxia, 2011) and found the connection between different dimension of reward satisfaction and organizational commitment. Also some scholars explored relationship of organizational commitment and turnover intention and it's concluded that there is a negative correlation relationship between organizational commitment and turnover intention, especially the ideal commitment and AC have stronger prediction function to turnover intention (Wang Jing \& Chen Zibing, 2011; Sun Haiyan, 2010). Although organizational commitment is a psychological commitment to the organization for the employees, it can be predicted by reward satisfaction. Also, 
turnover intention as a psychological state before departure behavior, organizational commitment also has certain prediction effect. Based on this, this paper establishes research framework to research the relationship between the three, and tries to study the mediating effect of organizational commitment to reward satisfaction and turnover intention.

\subsection{Measurement of Reward Satisfaction, Organizational Commitment and Turnover Intention}

In this paper, reward satisfaction scale is designed by the author according to the interview results from the caddie director and literature review. There are 14 items and they're tested with Likert five-point scale measurement. The higher score, the higher the reward satisfaction.

Organizational commitment is measured with Allen and Meyer three factors model. Each dimension has 8 items and items also measured with Likert five-point scale measurement.

Turnover intention scale is selected by the theory proposed by Griffith \& Hom, Mobley which is most widely used and is a total of three questions. Items also measured with Likert five-point scale measurement and the higher the score, on behalf of the higher turnover intention.

\section{Method}

\subsection{Research Structure}

This study explores the relationship between caddies' reward satisfaction, organizational commitment and turnover intention. The conceptual framework of this study on which the empirical analysis is based is concluded from literature review. Items of reward satisfaction scale, Organizational commitment scale and turnover intention scale are tested with Likert five-point scale measurement.

\subsection{Research Hypotheses}

The literature review and research framework reveal that the caddies' turnover intention exerts impact on degree of reward satisfaction, organizational commitment. The research hypotheses are proposed (Figure 1).

\subsection{Research Subjects and Sampling}

This study takes the golf club in Shenzhen, China as the target, and the caddies as the subjects. This study distributed 800 questionnaires in four golf clubs to ensure the survey accuracy and 685 questionnaires are distri-

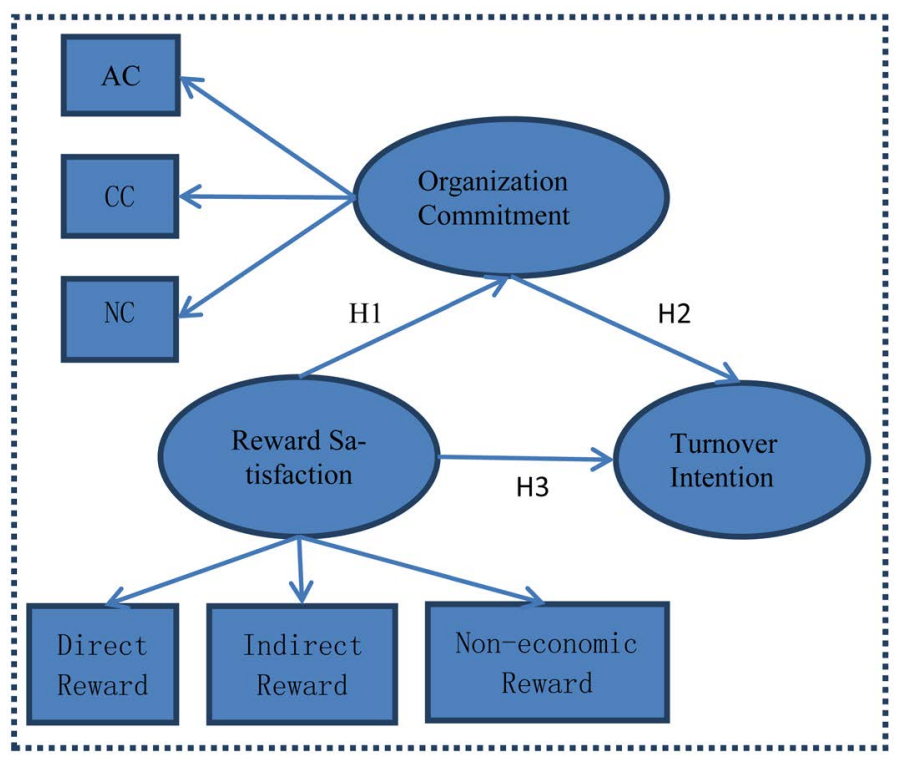

Figure 1. The structure of research. 
buted. Before the formal investigation, the author in-depth interviewed each club caddy director and individual caddie, and reference at home and abroad reward satisfaction scale, editing the reward satisfaction scale, a total of 14 item, make a preliminary investigation.

\section{Results}

\subsection{Reliability and Validity and Factor Analysis}

Adopt SPSS19.0 to test the scale Cronbach's Alpha of reward satisfaction, organizational commitment and turnover intention. The value of the scale Cronbach's Alpha is 0.930, 0.966, 0.856 (Table 1), indicating that the scale dimensions all have relatively high reliability, i.e. the survey scale has good internal consistency. Using principal component analysis and varimax rotation carries on the exploratory factor analysis of variance. KMO and Bartlett's test of sphericity display that sample is suitable for factor analysis (Table 1).

\subsection{Descriptive Statistic Analysis of Socio-Economic Background and Features of Caddies}

The descriptive statistic analysis is carried out on the personal information of the caddies, including gender, marriage, age, educational status, caddies grade, years of working as Table 2. As for socio-economic background, most caddies are female (64.9\%) and unmarried (70.8\%), 20 - 25 years old (60.6\%), followed by young

Table 1. Correlation analysis, reliability and validity analysis.

\begin{tabular}{cccc}
\hline & Turnover intention & Reward satisfaction & Organizational commitment \\
\hline Turnover intention & $1 / 0.856 / 0.704$ & & \\
Reward satisfaction & $-0.218^{*}$ & $1 / 0.930 / 0.910$ & $1 / 0.966 / 0.945$ \\
\hline
\end{tabular}

Note: ${ }^{* *} \mathrm{p}<0.01 ;{ }^{*} \mathrm{p}<0.05$.

Table 2. Demographic characteristics of the caddies.

\begin{tabular}{|c|c|c|c|}
\hline Items & Category & Frequency & Percent (\%) \\
\hline \multirow{2}{*}{ Gender } & Female & 520 & 65.0 \\
\hline & Male & 280 & 35.0 \\
\hline \multirow{4}{*}{ Age } & $<20$ & 222 & 27.7 \\
\hline & $20-25$ & 485 & 60.6 \\
\hline & $26-30$ & 87 & 10.9 \\
\hline & $>30$ & 6 & 0.7 \\
\hline \multirow{2}{*}{ Marriage } & Unmarried & 566 & 70.8 \\
\hline & Married & 234 & 29.2 \\
\hline \multirow{3}{*}{ Education } & Junior high school education or below & 193 & 24.1 \\
\hline & Secondary & 537 & 67.2 \\
\hline & Junior college & 70 & 8.8 \\
\hline \multirow{3}{*}{ Caddies’ grade } & Grade B & 216 & 27.0 \\
\hline & Grade C & 374 & 46.7 \\
\hline & Grade D & 210 & 26.3 \\
\hline \multirow{5}{*}{ Working years } & $<1$ & 234 & 29.2 \\
\hline & $1-3$ & 374 & 46.7 \\
\hline & $3-5$ & 93 & 11.7 \\
\hline & $5-7$ & 70 & 8.8 \\
\hline & $>7$ & 29 & 3.6 \\
\hline
\end{tabular}

Note: $\mathrm{n}=800$. 
adults of 20 years old or below (27.7\%), 26 - 30 years old (11.7\%), Secondary (67.2\%), junior high school education or below (24.2\%), have university (junior college) background (8.6\%), most caddies are grade C (46.7\%), grade B (27.0\%) and grade D (26.3\%), most caddies working for 1 - 3 years (46.7\%), followed by one year or below (29.1\%), and 7 years or above (3.6\%).

\subsection{Pearson Product-Moment Correlation Analysis and Reliability Analysis}

Pearson product-moment correlation analysis was conducted to explore whether there is significant correlation between caddies' reward satisfaction, organizational commitment and turnover intention. This study also examined whether the variables of these dimensions reach the expected significance by one tailed significance test based on the hypothesis direction. The correlation analysis of the variables of visitor value, degree of satisfaction and loyalty is shown as in Table 1. The turnover intention is in negative correlation to reward satisfaction, organizational commitment. The organization commitment is in positive correlation to reward satisfaction.

\subsection{Regression Analysis}

Regression analysis further explore related structure between variables, especially the structure of causality is described. This section mainly explores predictive power of reward satisfaction on organizational commitment and turnover intention, and reward satisfaction on turnover intention. Take model 1, 2 as an example, the first time and second time respectively use reward satisfaction and direct reward, indirect reward, non-economic reward as independent variable, organizational commitment as dependent variable. In model 1, adjusted R2 is 0 . 607 , illustrates reward satisfaction has $60.7 \%$ explanatory power on organizational commitment. Model 2, indirect reward has the strongest predictive power $(0.718)$ on organizational commitment compared the other two dimension. In model 3, organizational commitment has $17.8 \%$ explanatory power on turnover intention. And CC and AC both can predict turnover intention While NC has not entered the regression equation. And reward satisfaction has $21.8 \%$ explanatory power on turnover intention when indirect reward has $34.3 \%$ (Table 3).

Table 3. Regression Analysis of caddies’ reward satisfaction, organizational commitment and turnover intention.

\begin{tabular}{|c|c|c|c|c|c|c|}
\hline & Model & Regression coefficient & Standard regression coefficient & $\mathrm{t}$ & Sig. & Adjusted $\mathrm{R}^{2}$ \\
\hline \multirow{3}{*}{1} & \multirow{2}{*}{$\begin{array}{c}\text { Constant } \\
\text { RS }\end{array}$} & 1.126 & - & 0.000 & 1.000 & \multirow{2}{*}{0.607} \\
\hline & & 0.781 & 0.781 & 14.520 & 0.000 & \\
\hline & Regression eguation & & $\mathrm{Y}(\mathrm{OC})=0.781 * \mathrm{RS}+1.126$ & & & \multirow{5}{*}{0.703} \\
\hline \multirow{5}{*}{2} & Constant & 1.630 & - & 0.000 & 1.000 & \\
\hline & IR & 0.718 & 0.718 & 15.368 & 0.000 & \\
\hline & DR & 0.322 & 0.322 & 6.886 & 0.000 & \\
\hline & NR & 0.299 & 0.299 & 6.397 & 0.000 & \\
\hline & Regression eguation & \multicolumn{4}{|c|}{$\mathrm{Y}(\mathrm{OC})=0.781 * \mathrm{IR}+0.322 * \mathrm{DR}+0.299 * \mathrm{NR}+1.630$} & \\
\hline \multirow{3}{*}{3} & Constant & 1.415 & & 5.279 & 0.000 & \multirow{2}{*}{0.178} \\
\hline & OC & -0.438 & -0.429 & -5.515 & 0.000 & \\
\hline & Regression eguation & & $\mathrm{Y}(\mathrm{TI})=-0.438 * \mathrm{OC}+1.415$ & & & \multirow{4}{*}{0.186} \\
\hline \multirow{4}{*}{4} & Constant & -1.586 & - & 0.000 & 1.000 & \\
\hline & $\mathrm{CC}$ & -0.335 & -0.335 & -4.331 & 0.000 & \\
\hline & AC & -0.294 & -0.294 & -3.795 & 0.000 & \\
\hline & Regression eguation & & $=-0.335 * \mathrm{CC}-0.294 * \mathrm{AC}-$ & & & \\
\hline \multirow{3}{*}{5} & Constant & -1.304 & & 0.000 & 1.000 & \multirow{2}{*}{0.041} \\
\hline & RS & -0.218 & -0.218 & -2.599 & 0.010 & \\
\hline & Regression eguation & & $\mathrm{Y}(\mathrm{TI})=-0.218 * \mathrm{RS}-1.304$ & & & \multirow{4}{*}{0.111} \\
\hline \multirow{3}{*}{6} & Constant & -1.851 & & & & \\
\hline & IR & -0.343 & -0.343 & -4.238 & 0.000 & \\
\hline & Regression eguation & & $\mathrm{Y}(\mathrm{TI})=-0.343 * \mathrm{IR}-1.851$ & & & \\
\hline
\end{tabular}

Note: RS = reward satisfaction; IR = Indirect Reward; DR = direct Reward; NR = Non-economic Reward; OC = organization commitment; TI = turnover intention. 


\subsection{Mediating Effect of Organizational Commitment}

1) If in one study, the independent variable $X$ has an impact on the dependent variable $Y$, but may also through an intermediary variable $\mathrm{M}$ has indirect effect on $\mathrm{Y}$, rather than the direct effect of $\mathrm{X}$ to $\mathrm{Y}, \mathrm{M}$ is called intervening variable (Wen Zhonglin, Chang Lei, \& Hau Keitai, 2004). The effect of intervening variable divided into complete and partial mediation effect (Figure 2 and Figure 3).

2) If $\mathrm{X}, \mathrm{M}, \mathrm{Y}$ is decentration, the relationship of them can be described in the following equation.

$$
\begin{aligned}
& Y=c X+e_{1} \\
& M=a X+e_{2} \\
& Y=c^{\prime} X+\mathrm{b} M+\mathrm{e}_{3}
\end{aligned}
$$

Path diagram as follow (Figure 4):

3) Refer to the test program of Wen Zhonglin (Wen Zhonglin, Chang Lei, \& Hau Keitai, 2004), complete test program is as follows (Figure 5):

4) Test mediating effect of organizational commitment

A refers to regression coefficient of caddies' reward satisfaction on organizational commitment, b refers to organizational commitment on turnover intention and c refers to reward satisfaction on turnover intention. Therefore c' means that regression coefficient of organizational commitment, as intervening variable between reward satisfaction and turnover intention and playing mediating effect. The result is showed in Table 4. Step 1 , $\mathrm{c}=-0.218$, $\mathrm{t}$ is significant, step 2, $\mathrm{a}=0.781$, $\mathrm{t}$ is significant, $\mathrm{b}=-0.438$, $\mathrm{t}$ is significant; step 3 , c' $=0.294$, $\mathrm{t}$ is significant. Therefore, mediating effect of organizational commitment is significant and partial. Golf caddies’ reward satisfaction has significant impact on turnover intention, while partly through organizational commitment and ultimately to turnover intention.

\section{Discussion}

According to the empirical results analysis in this study, caddies' reward satisfaction has a significant positive impact on organizational commitment (H1), caddies' reward satisfaction and organizational commitment have a

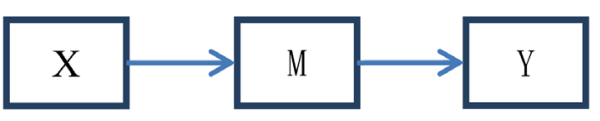

Figure 2. Complete mediation effect.

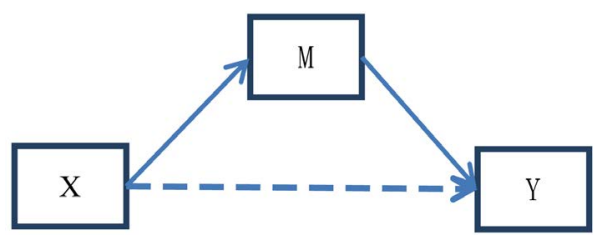

Figure 3. Partial mediation effect.
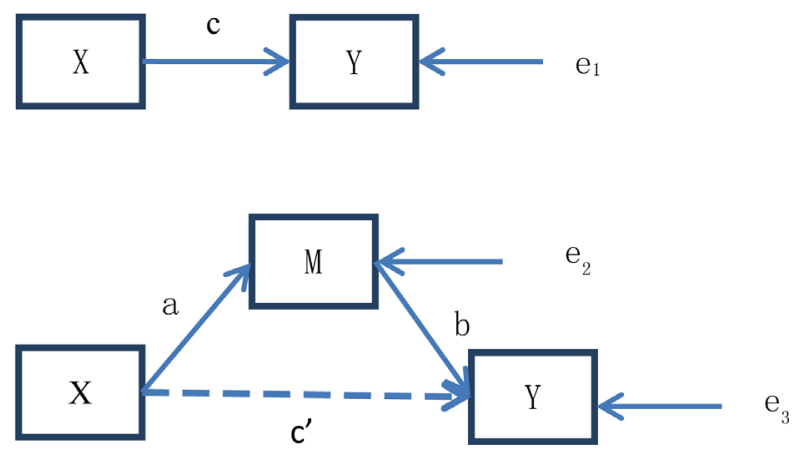

Figure 4. Mediating effect path diagram. 


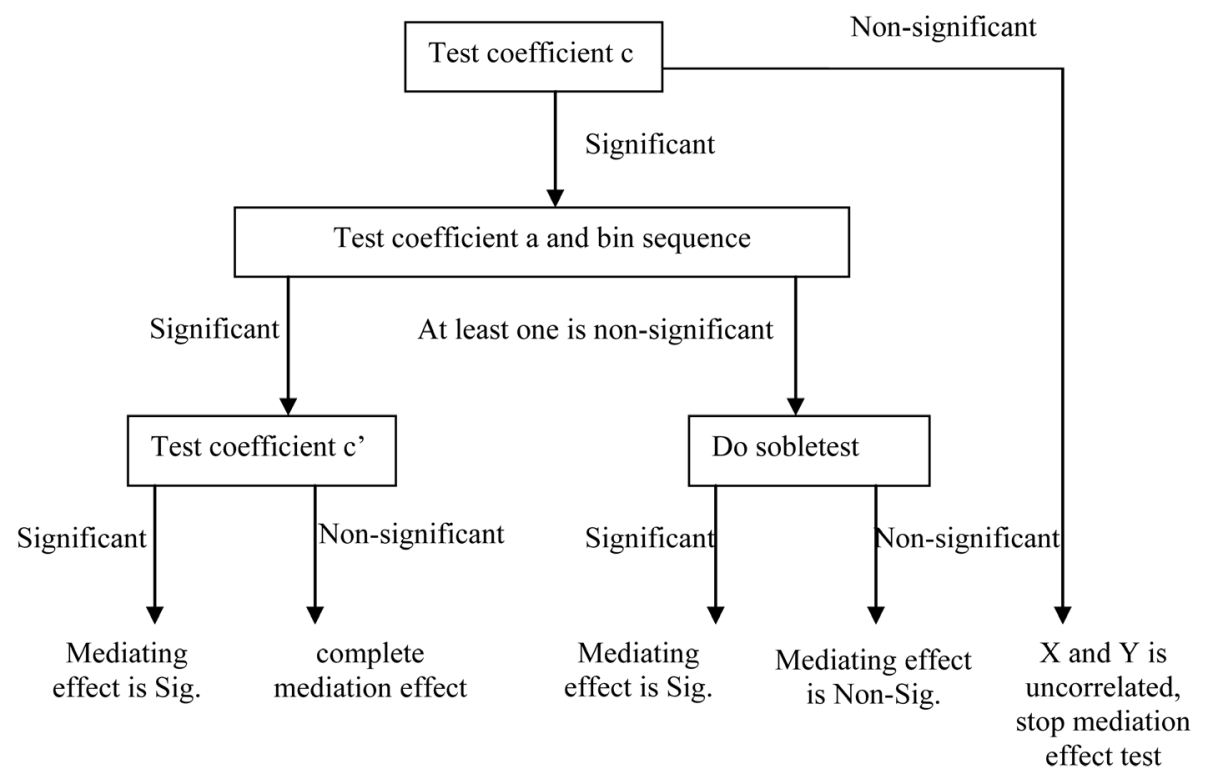

Figure 5. Test program of mediation effect.

Table 4. Test mediating effect.

\begin{tabular}{ccc}
\hline Steps & Standardized regression equation & Test regression coefficient \\
Step 1 & $\mathrm{y}=-0.218 \mathrm{x}-1.304$ & Sig $=0.010, \mathrm{t}=-2.599^{*}$ \\
Step 2 & $\mathrm{M}=0.781 \mathrm{x}+1.126$ & Sig $=0.000, \mathrm{t}=14.520^{* * *}$ \\
& $\mathrm{y}=-0.438 \mathrm{~m}+1.415$ & Sig $=0.000, \mathrm{t}=-5.515^{* * *}$ \\
Step 3 & $\mathrm{y}=0.294 \mathrm{x}-0.656 \mathrm{~m}-1.222$ & Sig $=0.018, \mathrm{t}=2.399^{*}$ \\
\hline
\end{tabular}

Note: ${ }^{*} \mathrm{p}<0.05,{ }^{* *} \mathrm{p}<0.01,{ }^{* * *} \mathrm{p}<0.001$.

significant negative impact on turnover intention (H2, H3), and affective commitment and continual commitment can predict turnover intention. Caddies' organizational commitment has a mediating effect between the relationship of reward satisfaction and turnover intention (H4). The sample data shows that golf caddies have higher turnover intention. The main reasons include the nature of work and wage. First, the job requires good physical quality but most caddies in China are female whose physical quality is best between 20 to 30 years old and most of them will leave at about 30 years old. Second, caddies' working strength is big while pay structure is not reasonable. Third, golf club generally lacks of career planning for caddies and caddies' opportunities for advancement is less. Otherwise, previous research mostly studied the relationship of the two of job satisfaction, organizational commitment and turnover intention. This paper designs the scale of reward satisfaction and research the relationship of the three. Results that reward satisfaction is positive with organizational commitment, negative with turnover intention; organizational commitment is positive with turnover intention are similar with previous study while relationships between different dimensions are different. For instance, indirect reward is negative with turnover intention while direct reward and non-economic reward have no correlation with it. It may be related to the sample as most clubs in Shenzhen adjusted caddies' basic wage and appearance fee, so caddies may consider more about indirect reward such as social benefits, career planning and promotion, etc.

\section{Conclusion}

In summary, this paper makes a contribution to the literature on caddies' reward satisfaction, organizational commitment and turnover intention and studies the relationship of the three and proves the hypotheses. Particularly, it studies the mediating effect of organizational commitment. It shows that reward satisfaction itself has significant impact on turnover intention, but some are affected by organizational commitment and ultimately af- 
fect turnover intention. Therefore, managers of golf clubs can reduce the turnover intention through improving caddies' reward satisfaction as well as further enhancing organizational commitment. Yet there are many other factors needed to study deeply in the future which may affect turnover intention such as organizational justice, psychological contract.

\section{References}

Adier, S., \& Skov, R. (1985). Job Characteristics and Job Satisfaction: When Becomes Consequence. Organization Behavior and Human Decision Procession, 35, 266-278. http://dx.doi.org/10.1016/0749-5978(85)90039-1

Becker, H. S. (1960). Notes on the Concept of Commitment. American Journal of Sociology, 66, 58-60. http://dx.doi.org/10.1086/222820

Byars, L. L., \& Rue, L. W.劳埃德 - 拜厄斯, 莱斯利 • 鲁 (2005). Renli ziyuan guanli (5th ed.)人力资源管理. Beijing: RenminYoudian Chubanshe.

Huang Rui 黄莣 (2011). Xinchou manyidu yu zuzhi chengnuo guanxi yanjiu—Yi anshan zhuangshi hangye wei li 薪酬满意 度与组织承诺关系研究——以鞍山装饰行业为例. M.S. Thesis, Shenyang: Liaoning Daxue.

Lai Xiaoxia 赖小霞 (2011). Zhongxue jiaoshi xinli ziben, xinchou manyidu yu zuzhi chengnuo de guanxi yanjiu 中学教师心 理资本、薪酬满意度与组织承诺的关系研究. M.S. Thesis, Shanghai: Huadong Shifan Daxue.

Liu Xin 刘昕 (2002). Xinchou guanli 薪酬管理. Beijing: Zhongguo Renmin Daxue Chubanshe.

Meyer, J. P., \& Allen, N. J. (1997). Commitment in the Workplace: Theory, Research, and Application. Thousand Oaks, CA: Sage.

Ran Bin 再斌 (2002). Xinchou sheji yu guanli 薪酬设计与管理. Shenzhen: Haitian Chubanshe.

Robinson, S. L., \& Morrison, E. W. (1995). Organizational Citizenship Behavior: A Psychological Contract Perspective. Journal of Organizational Behavior, 1, 289-298. http://dx.doi.org/10.1002/job.4030160309

Robinson, S. L., \& Russeau, D. M. (1994). Violating the Psychological Contract: Not the Exception but the Norm. Journal of Organizational Behavior, 15, 245-259. http://dx.doi.org/10.1002/job.4030150306

Sun Haiyan 孙海燕 (2010). Fandian qiye wenhua, zuzhi chengnuo yu lizhi qingxiang de guanxi yanjiu 饭店企业文化、组 织承诺与离职倾向的关系研究. M.S. Thesis, Hangzhou: Zhejiang Daxue.

Wang Jing 王婧, \& Chen Zibing 陈子兵 (2011). Zhishixing yuangong zuzhi chengnuo yu lizhi qingxiang guanxi de shizheng yanjiu 知识型员工组织承诺与离职倾向关系的实证研究. Huadong Shifan Daxue Jingji Yanjiu Daokan, 3, 108109.

Wen Zhonglin 温忠麟, Chang Lei 张雷, \& Hau Keitai 侯杰泰 (2004). Zhongjie xiaoying jianyan chengxu jiqi yingyong 中介效应检验程序及其应用. Xinli Xuebao, 36, 614-620.

Wiener, Y. (1982). Commitment in Organization: A Normative View. Academy of Management Review, 7, 418-428. http://dx.doi.org/10.2307/257334

Xin Xun 辛迅 (2006). Zhishixing yuangong quanmian xinchou manyidu yu zuzhi chengnuo guanxi de shizheng yanjiu 知识 型员工全面薪酬满意度与组织承诺关系的实证研究. M.S. Thesis, Chengdu: Xinan Jiaotong Daxue.

Yang Qingtao 杨清涛 (2010). Qiye yuangong gongzuo yali, gongzuo manyidu yu lizhi qingxiang de guanxi yanjiu 企业员工 工作压力、工作满意度与离职倾向的关系研究. M.S. Thesis, Jilin: Jilin Daxue.

Zeng Xiangquan 曾湘权 (2003). Zhongguo Qiye de xinchou wenti yu xinchou sheji 中国企业的薪酬问题与薪酬设计. Zhongguo Rencai, 2, 22-23.

Zhong Jianwei 钟建伟 (2008). Jiudian yuangong de gongzuo manyidu, zuzhi chengnuo yu lizhi qingxiang guanxi yanjiu 酒 店员工的工作满意度、组织承诺与离职倾向关系研究. M.S. Thesis, Chongqing: Xinan Daxue. 